JURNAL GEOGRAFI

Geografi dan Pengajarannya

ISSN 1412 - 6982

e-ISSN : 2443-3977

Volume XVIII Nomor 1 Juni 2020

\title{
MENYIMAK FENOMENA TSUNAMI SELAT SUNDA
}

\author{
Anis Fauzi, Hunainah, dan Humaedi \\ UIN Sultan Maulana Hasanuddin Banten
}

\begin{abstract}
Abstrak: Tsunami sebagian besar disebabkan oleh gempa bumi di dasar laut. Selain itu tsunami juga bisa dipicu akibat tanah longsor di dasar laut, letusan gunungapi dasar laut, ekstrusi gas, jatuhnya benda-benda langit, ledakan nuklir, dan sumber pembangkit lainnya. Penelitian ini adalah field research (penelitian lapangan), yang menitik beratkan pada hasil pengumpulan data dari informan yang ditentukan. Penelitian lapangan ini dilakukan secara langsung dimana objek yang diteliti yaitu masyarakat atau warga yang terdampak tsunami Selat Sunda. Jika ditinjau dari sifat penelitian, penelitian ini digolongkan ke dalam penelitian deskriptif, yakni mempelajari masalahmasalah dalam masyarakat, serta tata cara yang berlaku dalam masyarakat serta situasi-situasi tertentu, termasuk tentang hubungan, kegiatan-kegiatan, sikap-sikap, pandangan-pandangan, serta proses-proses yang sedang berlangsung dan pengaruh-pengaruh dari suatu fenomena. Bencana tsunami di Selat Sunda memberikan dampak psikologis bagi masyarakat di wilayah Banten dan sekitarnya. Traumatik akibat bencana tsunami yang mereka alami perlu mendapatkan penanganan yang serius. Bantuan berupa konseling untuk mereduksi traumatik mereka belum banyak dilakukan.
\end{abstract}

Kata kunci: Fenomena, Dampak, Sunami, Selat Sunda

\section{A. PENDAhuluan}

Indonesia adalah negara yang rawan tsunami, karena merupakan daerah pertemuan tiga lempeng tektonik utama dunia, yakni Lempeng Eurasia, Lempeng Indo-Australia dan Lempeng Pasifik. Sejumlah daerah di pulau-pulau yang berhadapan langsung dengan zona penunjaman antar lempeng ini, seperti bagian barat Pulau Sumatra, selatan Pulau Jawa, Nusa Tenggara, bagian utara Papua, serta Sulawesi dan Maluku merupakan kawasan yang sangat rawan

\footnotetext{
${ }^{1}$ Masterplan Pengurangan Risiko Bencana Tsunami, Menuju Indonesia Tangguh Menghadapi Tsunami, (Badan
}

tsunami. Catatan sejarah tsunami di Indonesia menunjukkan bahwa kurang lebih 172 tsunami yang terjadi dalam kurun waktu antara tahun 1600-2012. ${ }^{1}$ Berdasarkan sumber pembangkitnya diketahui bahwa 90\% dari tsunami tersebut disebabkan oleh aktivitas gempabumi tektonik, 9\% akibat aktivitas vulkanik dan $1 \%$ oleh tanah longsor yang terjadi dalam tubuh air (danau atau laut) maupun longsoran dari darat yang masuk ke dalam tubuh air.

Nasional Penanggulangan Bencana, Juni 2012) h.11

Alamat korespondensi :

E-mail : Jantera_Anis@yahoo.com 


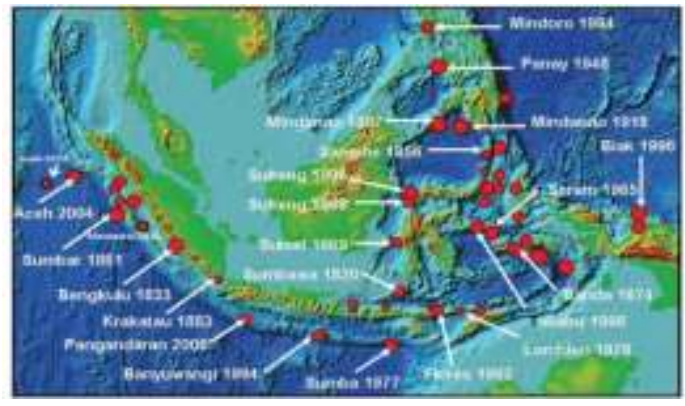

Gambar 1 Lokasi Kejadian Gempa

Bumi dan Tsunami di Indonesia

Dalam dua dekade terakhir terjadi sedikitnya sepuluh kejadian bencana tsunami di Indonesia. Sembilan di antaranya merupakan tsunami yang merusak dan menimbulkan korban jiwa serta material, yaitu tsunami di Flores (1992), Banyuwangi, Jawa Timur (1994); Biak (1996); Maluku (1998); Banggai; Sulawesi Utara (2000); Aceh (2004); Nias (2005); Jawa Barat (2006); Bengkulu (2007); dan Mentawai (2010). Dampak yang ditimbulkan tsunami tersebut adalah sekitar 170 ribu orang meninggal dunia. ${ }^{2}$

Dengan demikian dapat diambil kesimpulan Tsunami yang terjadi di selat sunda di masa lampau di pengaruhi oleh kondisi geologi dan tektonik di wilayah ini, dengan demikian sumber sunamigenik di perairan Selat Sunda

\footnotetext{
2 ...............Menuju Indonesia Tangguh Menghadapi Tsunami, (Badan Nasional Penanggulangan Bencana, Juni 2012) h. 12

$$
\text { Budiono, Yudhicara, }
$$
Tsunamigenik di Seat Sunda: Kajian Terhadap Katalog Tsunami Soloviev, Jurnal
}

dapat diakibatkan oleh gempa bumi yang berkaitan dengan subduksi Sunda, erupsi gunung berapi bawah laut Krakatau, longsoran di pantai, dan longsoran bawah laut di sekitar Selat Sunda. ${ }^{3}$

Gelombang tsunami bergerak sangat cepat, mencapai 600-800 km per jam, dengan tinggi gelombang dapat mencapai $20 \mathrm{~m}$. Pada sub bab ini agar disebutkan/diterangkan sejarah kejadian tsunami yang pernah terjadi di daerah ini, dan lokasi-lokasi pantai yang rawan tsunami. ${ }^{4}$ Tsunami di Selat Sunda dapat disebabkan oleh gempa tektonik di perairan Selat Sunda maupun Samudera Hindia; atau dipicu oleh gempa vulkanik akibat aktivitas Gunung Anak Krakatau. Kerusakan akibat gelombang tsunami terutama terjadi pada daerah teluk akibat terjadinya penyempitan gerakan gelombang sehingga mempercepat gerakan gelombang tersebut. Kecepatan tsunami lebih besar pada laut dalam dibandingkan laut dangkal, karena pada laut dangkal kecepatan gelombang banyak dinetralisir oleh dasar laut yang semakin dangkal sementara pada laut dalam gelombang bergerak tanpa

Geologi Indonesia, Vol.3 No. 4 Desember 2008: 24-251

${ }^{4}$ Peraturan Kepala Badan Nasional Penanggulangan Bencana Nomor 4 Tahun 2008 tentang Pedoman penyusunan Renacana Penanggulangan Bencana h.9-10 
hambatan. Patahan merupakan salah satu penyebab terjadinya gempa berjenis gempa tektonik. Energi kinetik yang timbul pada patahan berubah menjadi energi gelombang.

Pulau Jawa memiliki banyak patahan aktif. Ada tiga pola patahan utama di Pulau Jawa, yaitu: Pola Sumatera, Pola Jawa, dan Pola Sunda, Selain patahan, aktivitas vulkanik juga dapat menyebabkan gempa, dengan jenis gempa vulkanik. Pusat gempa jenis ini akan mengikuti jalur gunung api di Indonesia. Gempa jenis ini umumnya akan mempunyai pusat gempa di bawah permukaan (episenter) yang dangkal, sehingga bersifat lebih merusak. ${ }^{5}$

Heru Sri Naryanto (2006) telah membahas potensi seismisitas dan tsunami di Selat Sunda dalam paparannya yang berjudul "Kesiapan Mengantisipasi Bencana Industri Di Provinsi Banten". Khusus untuk kawasan Selat Sunda, kegempaan di wilayah ini menunjukkan aktivitas yang besar. Kegempaan di Selat Sunda dengan skala di atas 2,5 skala Richter pada tahun 1985 terjadi sebanyak 29 kali, tahun 198614 kali, tahun 1987 sebanyak 8 kali, tahun 1988 sebanyak 13 kali, tahun 1989 sebanyak 12 kali dan tahun 1990

\footnotetext{
${ }^{5}$ Rencana Kontinjensi Kota Cilegon Dalam Menghadapi Ancaman Gempa
}

sebanyak 6 kali. Berdasarkan pencatatan telemetri didapatkan angka sebanyak 2.456 kali gempa pada tahun 1994, dan paling kecil sebanyak 1.692 kali tahun 1993. Titik pusat gempa dapat dilihat pada Gambar 1. Seismisitas di Selat Sunda Tahun 2006.

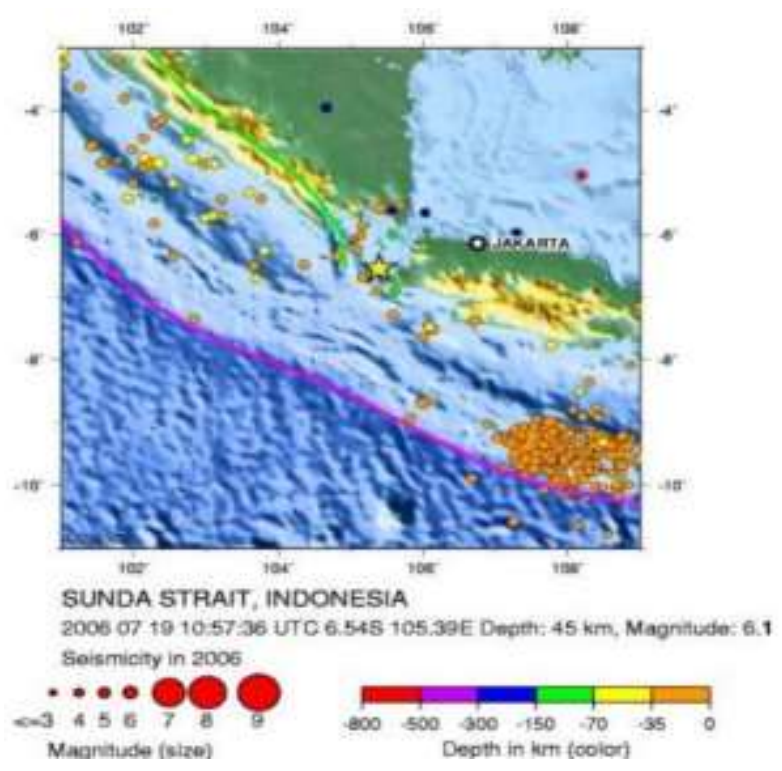

\section{Gambar 2 Seismisitas di Selat Sunda Tahun 2006}

Gambar 2 adalah peta seismisitas atau peta pusat gempa tahun 2006 di Wilayah Selat Sunda yang ditandai oleh rekaman titik gempa berwarna jingga (10 titik), warna hijau (2 titik), dan warna biru (2 titik) dengan intensitas umumnya magnitude 5-6 pada kedalaman 0-35 km di bawah muka laut. Lebih jauh lagi, gempa dengan magnitude 7, 8, dan lebih dari 8 sempat terekam sejak tahun 1900 .

Bumi/Tsunami 2010, Tanggal 28 Juli sampai 1 agustus 2010. h.21-22 
Terdapat 1 titik gempa di Selat Sunda pada kedalaman 0 hingga $35 \mathrm{~m}$ dibawah muka laut. Pusat gempa antara tahun 1900-1999 dengan magnitude >4 umumnya terjadi di Lautan Hindia dan Selat Sunda dengan frekuensi 6-29 kali per tahun. Konsentrasi pusat gempa berada di 3 lokasi, yaitu di bawah G. Krakatau, pada graben (sesar turun) di sebelah barat Selat Sunda, dan di selatan Sumatera. Beberapa pusat gempa yang telah terjadi di daratan umumnya terjadi di Banten Selatan (Kabupaten Lebak atau Kabupaten Pandeglang). ${ }^{6}$

\section{B. METODE PENELITIAN}

Jika ditinjau dari sifat penelitian, penelitian ini digolongkan ke dalam penelitian deskriptif, Menurut Witney, metode deskriptif adalah pencarian fakta dengan interpretasi tepat. ${ }^{7}$ Penelitian deskriptif ini mempelajari masalah-masalah dalam masyarakat, serta tata cara yang berlaku dalam masyarakat serta situasi-situasi tertentu, termasuk tentang hubungan, kegiatan-kegiatan, sikap-sikap, pandangan-pandangan, serta prosesproses yang sedang berlangsung dan pengaruh-pengaruh dari suatu fenomena. Moh Nazir menerangkan bahwa

\footnotetext{
${ }^{6}$ Rencana Kontinjensi Kota Cilegon Dalam Menghadapi Ancaman Gempa Bumi/Tsunami 2010, Tanggal 28 Juli sampai 1 agustus 2010. h.23
}

penelitian deskriptif mempelajari masalah-masalah dalam masyarakat serta situasi tertentu, termasuk tentang hubungan, kegiatan-kegiatan, sikapsikap, pandangan-pandangan, serta proses-proses yang sedang berlangsung dan pengaruh-pengaruh dari suatu fenomena. Jadi penelitian deskriptif dilihat dari tujuannya hanya untuk menggambarkan da metode pnelitian deskriptif ini hanya bersifat terbatas untuk menggambarkan dan melukiskan apa yang ada sekarang.

Sumber data dalam penelitian ini terbagi kedalam dua bagian yang pertama Data Primer dan Data Sekunder. Sumber data bagi penelitian kualitatif dengan metode sejarah dapat diklasifikasikan secara bermacam-macam. Antara lain : remain, dokumen, sumber primer, sumber sekunder, materi fisik, materi tulisan, dan sebagainya. ${ }^{8}$

Sumber primer dari penelitian ini adalah : 1). Fenomena kehidupan masyarakat terdampak tsunami di sekitar kawasan Selan Sunda Kabupaten Pandegalng Provinsi Banten Adapun sumber sekunder dalam penelitian ini dari buku-buku lain, majalah, artikel, dan

${ }^{7}$ Moh . Nazir, Metode Penelitian, (Jakarta:Ghalia Indonesia,2003) hlm 54-55.

${ }^{8}$ Mohamad Nazir, Metode penelitian, (Bogor : Ghalia Indonesia, 2014).hal.37. 
berita yang berkaitan dengan fokus penelitian.

Agar peneliti bisa mendapatkan data yang lebih valid dan akurat, maka dalam pengumpulan data peneliti menggunakan teknik-teknik pengumpulan data yang lazim digunakan dalam penelitian kualitatif, yaitu wawanara, observasi, dokumentasi, dan triangulasi.

\section{HASIL PENELITIAN DAN PEMBAHASAN}

\section{HASIL PENELITIAN}

\section{a. Kondisi Objektif Selat Sunda}

Lokasi korban bencana sunami Selat Sunda diantaranya terjadi di kp.Sidamukti yang berada di Kecamatan Sukaresmi Kabupaten Pandeglang Propinsi Banten Indonesia, Desa Sidamukti mempunyai beberapa Kampung yang terdiri dari Kp. Terusan, Kp. Sabang, Kp. Bintulang, Kp. Kubang Badak, Kp. Bayur, Kp. Kebon, Kp. Pesisir, Kp. Sidamukti, dan Kp. Jongor, jumlah RT. 26 dan Jumlah RW 7.

Desa Sidamukti berbatasan dengan Utara Desa Cibungur dan Desa Kubangkampil, .Sebelah Selatan Sungai Ciliman, Pasar Panimbang dan Desa Sukamaju, Sebelah Barat Selat Sunda, Sebelah Timur Desa Sukaresmi dan Desa Kubangkampil. Desa Sidamukti merupakan Desa yang di tempati oleh
Suku asli sunda, dan suku pendatang dari jawa Serang, Jawa Cirebon.
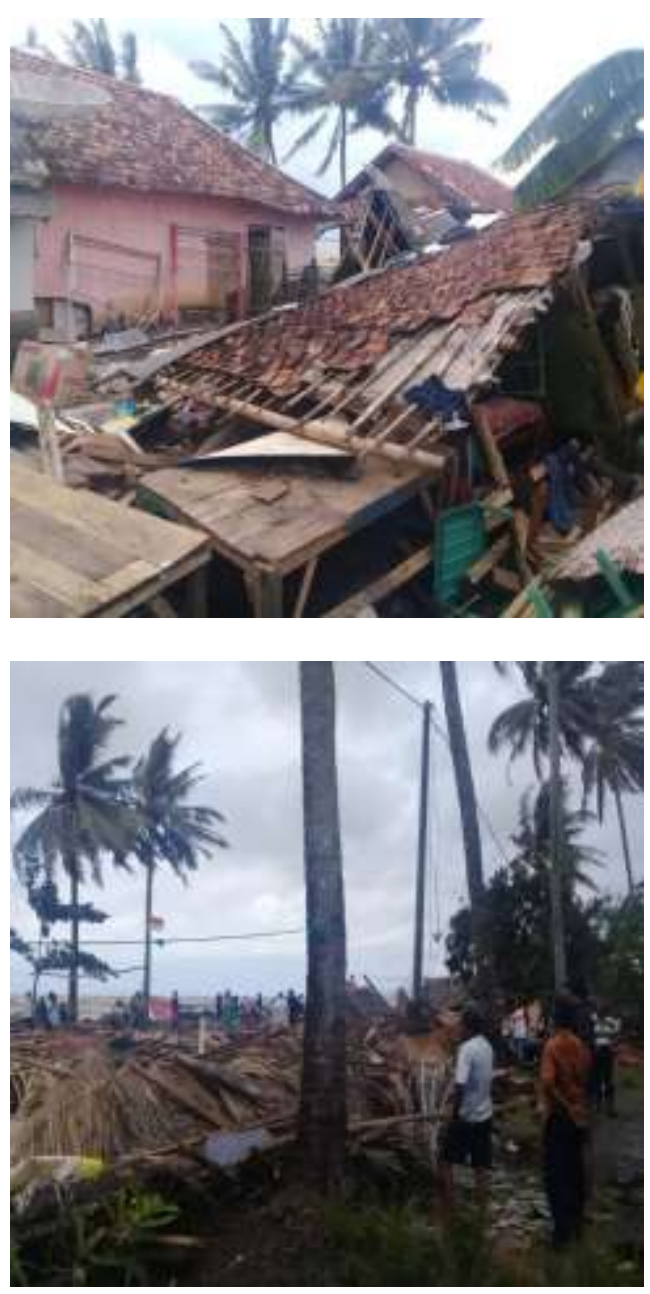

Gambar 3 Situasi pemukiman warga di Desa Sidamukti Kecamatan Sukaresmi Kabupaten Pandeglang yang diterjang ombak tsunami

Warga masyarakat Desa Sidamukti bermata pencaharian Petani, Nelayan, Pedagang. Desa Sidamukti di aliri oleh beberapa Sungai yang terdiri dari Sungai Ciliman, Sungai Sanggoma, Sungai Terusan, sungai Terusan Kidul, sungai Pinang Bongkok, adapun sungai terbesar adalah Sungai Ciliman kedua 
Sungai Sanggoma kemudian sungai Terusan.

Pada tanggal 22 Desember, laporan awal BNPB menunjukkan sedikitnya 20 orang tewas dan 165 terluka, dan 2 orang dilaporkan hilang. ${ }^{9}$ Pada tanggal 23 Desember, jumlah korban telah direvisi menjadi 43 tewas, 584 terluka, dan 2 hilang. Dari 43 korban jiwa, 33 tewas di Pandeglang, 7 di Lampung Selatan, dan 3 di Serang, dengan sebagian besar korban luka-luka (491 orang) juga di Pandeglang. Pada Minggu pukul 11:00 WIB, BNPB merevisi jumlah korban menjadi 62 tewas, 584 terluka, dan 20 hilang. ${ }^{10}$ Pada Minggu pukul 13:00 WIB, BNPB merevisi jumlah korban yakni 168 meninggal dunia dan 745 lukaluka. ${ }^{11}$ Wilayah yang terimbas tsunami di Pandeglang merupakan destinasi wisata seperti Pantai Carita. Menurut Sutopo, lokasi di Pantai Carita yang banyak ditemukan korban ialah di Hotel Mutiara Carita Cottage, Hotel Tanjung Lesung,

9 "Korban Tsunami Terus Bertambah, 20 Meninggal Dunia, 165 LukaLuka dan 2 Hilang". Badan Nasional Penanggulangan Bencana (dalam bahasa Inggris). Diakses tanggal 2018-12-23.

10 Prasetia, Andhika. "Update Korban Tsunami Banten: 62 Orang Tewas, 584 Luka, 20 Hilang". detiknews. Diakses tanggal 2018-12-23.

11 "Update Korban Tsunami Selat Sunda: 168 Orang Meninggal, 745 dan Kampung Sambolo. Memang daerah sana sedang dipadati wisatawan dan masyarakat setempat.

Tabel 1 data korban tsunami selat sunda

\begin{tabular}{rccc}
\hline \multirow{2}{*}{ TANGGAL } & \multicolumn{3}{c}{ JUMLAH KORBAN } \\
\cline { 2 - 4 } & Meninggal & Luka & Hilang \\
\hline $22-12-2018$ & 20 & 165 & 2 \\
$23-12-2018$ & 43 & 584 & 2 \\
$30-12-2018$ & 62 & 745 & 20 \\
$30-12-2018$ & 168 & & 20 \\
\hline JUMLAH & $\mathbf{2 9 3}$ & $\mathbf{1 4 9 4}$ & $\mathbf{4 4}$ \\
\hline
\end{tabular}

Pantai seperti Pantai Tanjung Lesung, Pantai Teluk Lada, Pantai Panimbang, Pantai Sumur, dan Pantai Carita memang sedang ramai oleh turis yang berlibur. $^{12}$ Pukul 16.00 WIB, Sutopo Purwo Nugroho menyatakan melalui akun Twitternya bahwa korban terus bertambah. Ia menyatakan bahwa korban meninggal telah mencapai 222 orang, 843 orang luka, dan 28 orang masih hilang. ${ }^{13}$

Terluka". detiknews. 23 December 2018. Diakses tanggal 23 December 2018.

12 Amrullah, Amri; P., Bayu Adji; Saputri, Dessy Suciati; Jaramaya, Rizky; Suryarandika, Rizky. (editor: Satria Kartika Yudha. 24 Desember 2018.). "Tsunami Senyap dari Selat Sunda". Republika. Hlm.1 13 "Tsunami terjang Selat Sunda, korban diperkirakan terus bertambah". $B B C$. 23 December 2018. Diakses tanggal 23 December 2018.

^ Perraudin, Frances; Ellis-Petersen 


\begin{tabular}{lccc}
\multicolumn{3}{c}{ Tabel 2 } & $\begin{array}{c}\text { Data Korban Tsunami Selat } \\
\text { Sunda }\end{array}$ \\
\hline \multirow{2}{*}{ Tanggal } & \multicolumn{2}{c}{ JUMLAH KORBAN } \\
\cline { 2 - 4 } & Meninggal & Luka & Hilang \\
\hline $24-12-2018$ & 281 & 1.016 & 57 \\
$25-12-2018$ & 429 & 1.485 & 154 \\
\hline JUMLAH & $\mathbf{7 1 0}$ & $\mathbf{2 5 0 1}$ & $\mathbf{2 1 1}$ \\
\hline \multirow{2}{*}{ Pada } & tanggal & 24 & Desember \\
2018, & Sutopo & & Purwo
\end{tabular}

Nugroho menyatakan bahwasanya hingga pukul 07.00 berdasarkan data yang dihimpun oleh BNPB, jumlah korban tewas sebanyak 281 orang, 1.016 terluka, dan 57 orang lainnya masih hilang. Pada 25 Desember, Humas BNPB menyatakan bahwa 429 orang meninggal, 1.485 orang luka-luka, 154 orang hilang, 16.082 orang mengungsi. Korban dan kerusakan yang terdampak ialah dari Kabupaten Pandeglang, Kabupaten Serang, Kabupaten Lampung Selatan, dan Kabupaten Tanggamus. Beberapa korban di antaranya adalah Heriyanto alias Aa Jimmy, seorang komedian, dan beberapa anggota grup musik Seventeen, di mana gitaris, basis, pemain drum dan manajer grup musik ditemukan meninggal dunia. ${ }^{14}$ Sebuah video yang beredar menunjukkan panggung tempat grup

14 "Sambil Menangis, Ifan Seventeen Kabarkan Gitaris dan Drummernya Hilang Saat Tsunami Banten". KOMPAS. musik Seventeen yang melaksanakan konser dalam rangka darmawisata rombongan karyawan PLN beserta keluarga di kawasan Tanjung Lesung tersapu oleh tsunami. Pada pukul 16.10 WIB, Detik.com melansir dalam acara wisata itu, PLN menyebut ada 29 korban meninggal dari pihak PLN, 157 orang selamat, dan 13 lainnya masih hilang. Pihak PLN yang ikut acara kumpul pegawai beserta keluarganya berjumlah 199 orang. Rombongan karyawan beserta keluarga dari Kementerian Pemuda dan Olahraga dan PLN yang sedang berwisata di sekitar pantai barat Banten turut menjadi korban, baik korban luka maupun korban jiwa, akibat tsunami. Sementara itu, rombongan santri SMA Islam Nurul Fikri Boarding School (NFBS) Serang yang menempati sebuah resor tepat di pinggir pantai di Umbul Tanjung selamat dari terjangan tsunami, walaupun bangunan di sekitar lokasi resor mereka luluh lantak akibat sapuan ombak. Sebuah video yang beredar di media sosial memperlihatkan tempat rombongan santri SMA Islam NFBS "utuh tak tersentuh". Seluruh rombongan sebanyak 55 santri selamat; mereka tengah melewati masa karantina menghafal Alquran dalam rangka

23 December 2018. Diakses tanggal 23 December 2018. 
persiapan pengambilan sanad ke Turki. ${ }^{15}$

Sekitar 400 rumah di Pandeglang yang terletak di dekat pantai roboh atau rusak berat akibat tsunami. Selain itu, 9 hotel di Pandeglang dan 30 rumah di Lampung Selatan juga rusak berat. Jalan raya yang menghubungkan Serang dan Pandeglang terputus. Kemudian, pada pukul 16.00, 23 Desember 2018, berita terbaru dari BNPB menyebutkan kerusakan material dari tsunami ini meliputi 556 unit rumah rusak, sembilan unit hotel rusak berat, 60 warung kuliner rusak, 350 kapal dan perahu rusak. Di Pandeglang sendiri, didapati 73 unit kendaraan rusak, dan 446 rumah rusak. Pendataan kerusakan bangunan masih terus dilakukan. ${ }^{16}$ Per 25 Desember, kerusakan material diketahui masih terus bertambah. 882 rumah yang rusak, 73 penginapan rusak dan 60 warung rusak. Pada kendaraan, tercatat bahwa 434 perahu dan kapal rusak, 24 kendaraan roda 4 rusak, 41 kendaraan roda 2 rusak. Selain itu pula, terdapat 1 dermaga rusak, dan 1 shelter rusak. Kemudian menurut laporan daripada $B B C$ Indonesia, hampir semua warung, toko, minimarket/swalayan kecil, termasuk di pantai-pantai wisata Anyer. Tumpukan puing ber serakan di

15 "Kisah Para Santri Penghapal Alquran Selamat dari Tsunami". Republika Online. 2018-12-26. Diakses tanggal 201812-26. tepi dan sudut jalan, yang sebagian besarnya oleh bangunan semi permanen. Ambulans dan mobil aparat berlalu lalang, dan di pelataran kantor polisi, telah berleret kantong dari jenazah yang telah ditemukan. Selain itu, di bidang kelistrikan, ada 146 gardu listrik yang telah dapat dinyalakan. 102 masih padam, dan 20 saluran udara tegangan menengah roboh karena diterjang tsunami. Di Lampung Selatan, Desa Kunjir, Way Muli, dan Canti, menjadi desa yang paling terdampak bencana. Republika mengutip salah satu kesaksian warga, bahwa di Way Muli, dalam waktu 4 menit, tsunami menghancurkan rumah-rumah yang ada. Gulungannya begitu tinggi, menggemuruh, dan terlihat ada kilat api. Desa yang semula memang padat penduduk dan rumah, menjadi rata dengan tanah. Sampai pagi 24 Desember, menurut CNN Indonesia, sudah ada 60 orang ditemukan meninggal dunia, 22 orang hilang, dan 258 orang luka-luka.

\section{b. Penyebab Tsunami Selat Sunda}

Di Indonesia kejadian tsunami sebagian besar disebabkan oleh gempa bumi. Kejadian gempa sangat berpotensi memicu longsoran bawah laut dan

16 Billiocta, Ya'cob (23 Desember 2018). "Update Data Korban Tsunami Banten Pukul 16.00: 222 Meninggal dan 843 Orang Luka". Merdeka. Diakses tanggal 23 Desember2018. 
banyak yang tidak menyadari akan kejadian ikutan tersebut, penyebabnya tempat kejadian longsoran sulit ditentukan posisinya. ${ }^{17}$ Katalog kejadian tsunami (Soloviev dan Go, 1974) mencatat 11 kali kejadian tsunami di Selat Sunda. Empat di antaranya disebabkan karena letusan GAK pada tahun 416, 1883, 1884, dan 1928, meskipun Data Dasar Gunung api Indonesia (Badan Geologi, 2011) tidak mencatat kejadian tsunami akibat letusan Krakatau tahun 1884 dan 1928. Sementara itu, tujuh kejadian lainnya disebabkan oleh gempa tektonik, yaitu tahun 1772, 1757, 1851, 1852, Oktober 1883, 1889, dan 1958. Meski demikian, landaan tsunami terbesar dalam sejarah kehidupan manusia hanya terjadi pada tahun 1883 yang dipicu oleh letusan katastropik GAK. Kejadian tsunami terkini di Selat Sunda terjadi pada 22 Desember 2018 sekitar pukul 21.05 WIB. Landaan tsunami ini mencapai beberapa lokasi di pesisir pantai Jawa bagian barat dan Lampung bagian selatan. ${ }^{18}$

Peristiwa tsunami ini banyak disebut oleh beberapa peneliti dengan sebutan "silent tsunami" dan penyebabnya masih menjadi kontroversi

${ }^{17}$ Heru Sri Naryanto, Kajian Bahya Tsunami Di Pantai Utara Kabupaten Serang, Jurnal Alami (ISSN: 2548-8635) Vol.3 No. 2 Th.2019 h.113 hingga sekarang. Sedikitnya terdapat tiga teori yang dapat menjadi sebab terjadinya tsunami (tsunamigenic), yaitu gempa tektonik, letusan gunungapi, dan longsoran massa. Peristiwa tsunami yang berasosiasi dengan letusan gunungapi adalah letusan gunungapi bawah laut, runtuhnya kaldera (caldera collapse), dan masuknya material letusan gunungapi dalam jumlah besar dan cepat ke dalam air. Sementara itu, longsoran massa yang dapat memicu tsunami dapat pula dipicu oleh gempa bumi atau letusan gunungapi berkekuatan besar yang mengakibatkan ketidakstabilan massa pada suatu lereng. Hipotesis terjadinya tsunami Selat Sunda 22 Desember 2018 dapat disebabkan oleh gempa bumi, letusan gunung api, dan longsoran massa, atau bahkan kombinasi dari ketiganya. Sebelum terjadinya tsunami pada 22 Desember 2018 sekitar pukul 21.05 WIB, terjadi gempa bumi tektonik sekitar pukul 20.55 WIB. $\begin{array}{llllll}\text { Tercatat } & 6 & \text { stasiun } & \text { seismik } & \text { di } & 4\end{array}$ gunungapi, yaitu GAK, Dempo, Gede, dan Tangkuban Parahu. GFZ-GEOPON Global Seismic Network yang ditempatkan disekitar Selat Sunda merekam gempa tektonik berkekuatan 5.1 M (https:// geofon.gfz-

18 Wahyudi Memed, Asdani Soehaimi, Hendra Gunawan, Dinamika Geologi Selat Sunda Dalam Pembangunan Berkelanjutan, ( Bandung : Badan Geologi, 2019). h. 117 
potsdam.de/eqinfo/list.php), dengan titik sumber gempa atau episenter di koordinat $105.44^{\circ} \mathrm{E}$ dan $6.15^{\circ} \mathrm{S}$ dengan kedalaman sumber gempa $0 \mathrm{~km}$. Pada laman lainnya, https://m.emsc.eu/earthquake/earthquake .php?evid=734380 tertera informasi kekuatan gempa dengan magnitudo 5 pukul 20.55 WIB dengan episenter gempa pada koordinat $6.16 \mathrm{~S}$ dan 105.67 E dengan kedalaman 5 kilometer. Kejadian gempa tektonik tersebut dapat menjadi hipotesis penyebab kejadian tsunami 22 Desember 2018 meskipun secara teoritis dan statistik peristiwa gempa tektonik sebagai pemicu tsunami memiliki kekuatan di atas $7 \mathrm{M}$. Jika kejadian gempa tersebut diperhitungkan bukan sebagai penyebab tsunami, maka hipotesis kedua adalah berasosiasi dengan letusan GAK. Selain karena lokasinya yang berada di Selat Sunda, GAK sedang mengalami fase letusan sejak 29 Juni 2018. Catatan RSAM yang merepresentasikan energi letusan, memperlihatkan dominasi amplitudo maksimum sejak 4 September hingga 8 Oktober 2018 sebagai representasi energi letusan GAK tertinggi sepanjang 2018. Dominasi peningkatan amplitude letusan lainnya terjadi mulai 17-20 November

Selat Sunda Dalam Pembangunan Berkelanjutan, h. 118

2018. Ketika terjadi tsunami 22 Desember 2018, energi letusan GAK dalam kondisi relatif kecil yang tercermin dari grafik RSAM yang rendah.

Hal yang sama juga mencerminkan kejadian letusan lateral pada 26 Desember 2018. Jika longsornya sebagian tubuh GAK yang menyebabkan terjadinya tsunami disebabkan oleh proses letusan maka diperlukan kekuatan letusan yang cukup besar untuk melongsorkan massa lebih dari $0,08 \mathrm{~km} 3$. Dengan demikian, secara teoritis, pelongsoran sebagain tubuh GAK harus terjadi pada periode puncak letusan, antara 4 September hingga 8 Oktober 2018. Hipotesis ketiga yang dapat dijadikan sebagai alasan pembangkit tsunami 22 Desember 2018 adalah longsoran massa dalam jumlah besar dan cepat pada suatu lereng yang tidak stabil. Posisi tubuh GAK yang berada pada tepi timur laut Kaldera Krakatau 1883 merupakan daerah dengan kelerengan yang relatif tidak stabil. Selain itu, pertumbuhan dan pelamparan material letusan GAK lebih berkembang ke arah barat, barat daya, dan selatan cenderung mengarah pada tekuk lerang dinding Kaldera Krakatau 1883. ${ }^{19}$ 
Selain ketiga hipotesis di atas, gabungan ketiga hipotesis tersebut secara teoritis dapat menjadi pemicu terjadinya tsunami. Gempa tektonik 22 Desember 2018 pukul 20.55 WIB dapat menggetarkan material hasil letusan GAK yang menumpuk di lerang baratbarat daya yang tidak stabil. Jika longsoran tubuh gunungapi tersebut terjadi secara cepat dan memotong saluran magma GAK, maka secara teoritis memungkinkan terjadinya proses pelepasan tekanan secara tiba-tiba yang memicu terjadi letusan lateral (lateral blast) secara tiba-tiba dan cepat. Dampak dari letusan lateral tersebut dapat berakibat pada pelepasan material dari sebagian tubuh GAK. Meski demikian, uraian di atas masih merupakan hipotesis yang perlu dibuktikan dengan penelitian lebih lanjut. ${ }^{20}$

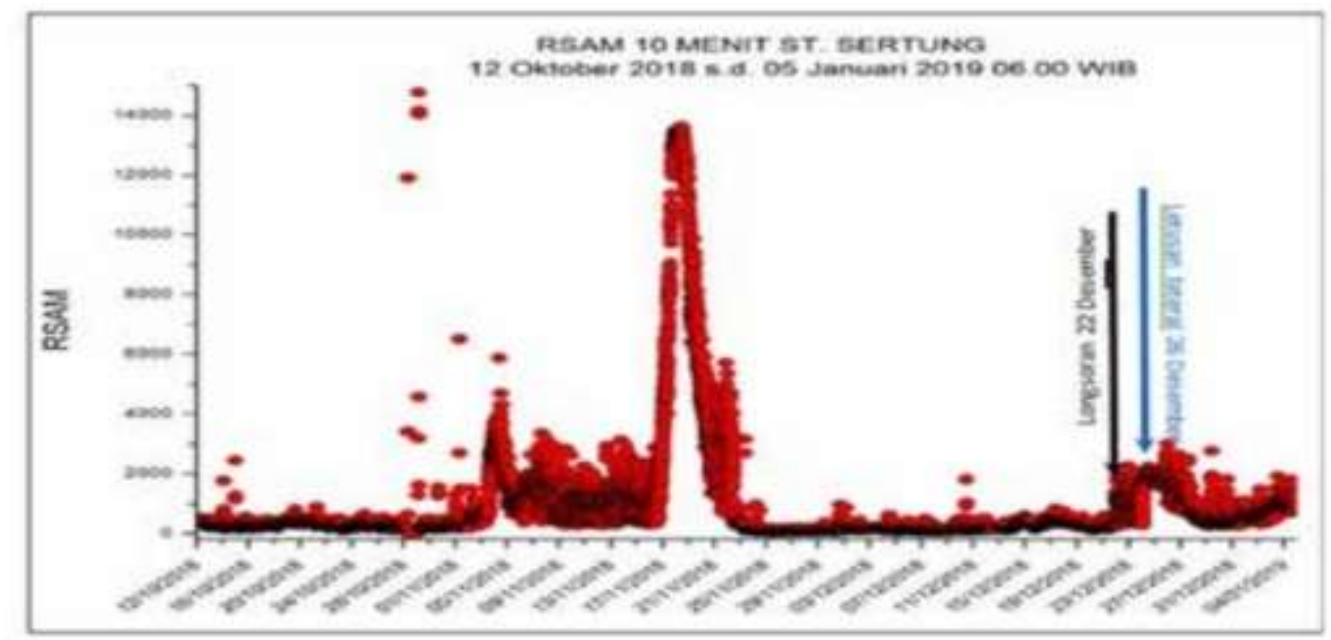

Gambar 4 : Grafik RSAM Stasiun Sertung di Pulau Sertung dan Korelasinya dengan kejadian Longsor 22 Desember 2018 dan letusan lateral 26 Desember 2018.

\section{c. Dampak Tsunami Selat Sunda}

Pada tanggal 22 Desember 2018, peristiwa tsunami yang disebabkan oleh letusan Anak Krakatau di Selat Sunda menghantam daerah pesisir Banten dan Lampung, Indonesia. Sedikitnya 426 orang tewas dan 7.202 terluka dan 23 orang hilang akibat peristiwa ini,menurut Dinamika Geologi Selat Sunda Dalam Pembangunan Berkelanjutan, h. 118-120
Badan Meteorologi, Klimatologi, dan Geofisika (BMKG), tsunami disebabkan pasang tinggi dan longsor bawah laut karena letusan gunung,berada di kawasan Cincin Api Pasifik, Indonesia menjadi tempat bagi 127 gunung api aktif dan peristiwa gempa bumi besar setiap 
tahunnya. Gunung Anak Krakatau yang terletak di Selat Sunda, salah satu di antara gunung api tersebut, merupakan gunung api yang muncul pada tahun 1927 setelah letusan Gunung Krakatau pada 1883. Letusan gunung ini merupakan salah satu yang mematikan sepanjang sejarah, menyebabkan megatsunami, dan gelombang awan panas, menewaskan lebih 30.000 jiwa, serta membuat kawasan sekitar letusan gunung tertutup abu vulkanik dan menghancurkan pesisir Banten dan Lampung. Beberapa bulan sebelum tsunami terjadi, Gunung Anak Krakatau menunjukkan peningkatan aktivitas, dengan terjadinya letusan pada 21 Desember 2018 selama 2 menit hingga menyemburkan abu vulkanik setinggi 400 meter (1300),Pada pukul 21:03 WIB (14:03 UTC), Anak Krakatau meletus dan merusak peralatan seismografi terdekat, meskipun suatu stasiun lain mendeteksi getaran terusmenerus. Pada pukul 21:27 WIB, BMKG mendeteksi suatu tsunami di pesisir barat Banten, meskipun tidak ada peristiwa tektonik,menurut fakta yang ada, terjadi longsoran dari Gunung Krakatau sebanyak 64 hektare yang memicu goncangan yang berujung kepada tsunami,juru bicara Badan Nasional Penanggulangan Bencana (BNPB) Sutopo Purwo Nugroho merilis sebuah pernyataan yang menghubungkan tsunami dengan pasang tinggi dan longsor bawah laut yang disebabkan oleh letusan Anak Krakatau.menurut kesaksian Indira Rezkisari (wartawan Republika) yang menyaksikan detikdetik terjadinya tsunami, sebelum terjadinya tsunami itu memang sempat terdengar dentuman keras dari laut. Selain itu pula, Republika 24 Desember mencatat bahwa bencana menerpa tanpa adanya peringatan dini dari sensor tsunami. Sebelumnya, BMKG telah mengeluarkan peringatan gelombang tinggi untuk perairan sekitar selat Sunda,tercatat tinggi gelombang tsunami berkisar 90 sentimeter (35 in) di Serang dan 30 sentimeter (12 in) di Lampung, dengan ketinggian maksimal 2 meter $(6,6$ ft).Ihwal gelombang itu pun sempat tercatat dalam cuitan Twitter BMKG, sebelum pada akhirnya dihapus pada pukul 01.01 WIB,namun pada akhirnya, BMKG memverifikasi bahwa tsunami memang terjadi pada sekitar 21.30 WIB, beriringan dengan kondisi gelombang tinggi karena bulan purnama di Selat Sunda pada 21-25 Desember. Øystein Lund Andersen, seorang fotografer gunung api asal Norwegia yang memotret letusan Anak-Krakatau sebelum tsunami pada hari yang sama, menggambarkan letusan itu sebagai ‘cukup besar,Andersen sendirian di pantai ketika gelombang tsunami datang, 
tetapi berhasil melarikan diri "The wave came out of nowhere," he said, "and within seconds I had to run." dalam sebuah wawancara dengan majalah Forbes.Setelah peristiwa tersebut, menerbitkan sebuah laporan saksi mata, dengan gambar-gambar yang memberi pandangan yang tak tertandingi tentang tsunami dan dampaknya. Tsunami yang menimpa daerah selatan pesisir Sumatra dan ujung barat Pulau Jawa ini tergolong langka, karena fenomena ini terjadi tanpa melalui gempa bumi terlebih dahulu. Pada tanggal 22 Desember, laporan data awal yang tercatat di kantor desa sidamukti 1 orang meninggal dunia dan, 1 orang dilaporkan hilang sedangkan rumah yang mengalami kerusakan sangat berat berjumlah 95 unit dan sisanya 26 unit mengalami kerusakan ringan, 14 unit perahu rusak berat dan 7 paket jaring hilang. ${ }^{21}$ Bencana tsunami juga dapat menimbulkan banyak sekali dampak atau kerugian yang diderita oleh warga.

Beberapa dampak dari bencana tsunami adalah sebagai berikut:

1. Terjadi kerusakan dimanamana. Dampak terjadinya tsunami yang pertama yaitu terjadinya kerusakan dimana- mana. Kerusakan yang dimaksud yaitu kerusakan fisik baik

${ }^{21}$ Website resmi desa Sidamukti di akses pada hari sabtu tanggal 08 Pebruari 2020 bangunan maupun non bangunan. Gelombang besar yang timbul karena tsunami ini dapat menyapu seluruh area daratan, baik daerah pantai maupun daerah- daerah di sekitar pantai tersebut. Kerusakan yang biasa terjadi yaitu di daerah yang terkena sapuan ombak. Gelombang ombak tersebut yang mempunyai kekuatan tinggi ini dalam sekejap dapat meluluh lantakkan seluruh bangunan, menyapu pasir atau tanah, merusak perkebunan dan persawahan masyarakat, merusak tambak dan ladang perikanan, dan lain sebagainya. Kerusakan yang terjadi ini dapat menimbulkan banyak kerugian, terutama kerugian berupa material.

2. Lahan pertanian dan perikanan rusak. Gelombang tsunami yang dasyat juga dapat menyebabkan lahan pertanian dan perikanan mengalami kerusakan. Gelombang tsunami dengan kekuatan yang besar dan gelombang yang tinggi mampu menyapu bersih apa saja yang ada di daratan. Jangankan tanaman yang ada di sawah maupun di perkebunan, bahkan bangunan pun banyak sekali yang roboh. Selain itu ikan- ikan yang dibudidaya di kolam perikanan juga akan 
tersapu oleh air dari gelombang tsunami tersebut.

3. Menghambat kegiatan perekonomian. Kita sepakat bahwa semua bencana alam dapat mengacaukan seluruh kegiatan perekonomian yang ada di suatu wilayah. Hal ini juga termasuk bencana tsunami tersebut. Kerusakan dan kehilangan yang terjadi akibat gelombang tsunami dapat melumpuhkan kegiatan perekonomian sampai beberapa waktu. Tidak hanya itu saja, namun kerugian yang telah disebabkan oleh tsunami mungkin akan menggantikan kegiatan produksi maupun perdagangan dalam waktu tertentu.

4. Kerugian material. Semua bencana alam dapat menimbulkan kerugian yang bersifat materiil, termasuk juga gelombang tsunami tersebut. Kerugian material diantaranya adalah karena robohnya bangunan, rusak lahan pertanian dan perikanan, dan kehilangan harta bendanya.

5. Kerugian spiritual. Selain kerugian yang bersifat material maupun yang dapat diukur dengan uang, bencana tsunami juga dapat menimbulkan kerugian yang bersifat spiritual. Yang dimaksud dengan kerugian spiritual yaitu kerugian yang tidak berupa harta benda, namun lebih ke jiwa. Bagaimana seorang anak kecil bahkan orang dewasa pun akan tabah setelah mengalami bencana alam yang besar, apalagi apabila ia kehilangan anggota keluarganya, maka hal itu dapat menimbulkan trauma di jiwa anak kecil. Akibatnya anak tersebut harus menjalani beberapa terapi agar terbebas dari traumanya tersebut. Bahkan hal seperti ini tidak hanya dialami oleh anak kecil saja, namun juga orang dewasa dan bahkan lanjut usia.

6. Menimbulkan bibit penyakit. Dampak selanjutnya dari bencana alam tsunami yaitu timbulnya bibit penyakit. Ketika gelombang laut yang tinggi meluluh lantakkan daratan, maka yang akan kitemukan merupakan bendabenda kotor, tanah yang berlumpur dan juga sebagainya. Lingkungan yang tidak bersih akan dapat menimbulkan bayak sekali bibit penyakit. Apalagi jika ditambah dengan jasad- jasad makhluk hidup yang telah meninggal, maka lingkungan akan semakin tidak sehat. Disamping itu, apabila tinggal di pengungsian maka yang akan terjadi yaitu timbulnya bibit penyakit karena kurangnya saranan dan pra sarana. Itulah beberapa dampak yang terjadi akibat bencana tsunami tersebut.

\section{PEMBAHASAN}

Bencana tsunami di Selat Sunda memberikan dampak psikologis 
bagi masyarakat di wilayah Banten dan sekitarnya. Traumatik akibat bencana tsunami yang mereka alami perlu mendapatkan penanganan yang serius. Bantuan berupa konseling untuk mereduksi traumatik mereka belum banyak dilakukan. Dalam perspektif bantuan pemulihan psikologis, konseling CBT (Cognitine Behavioral Therapy) menjadi alternatif solusi yang tepat dalam mereduksi masalah traumatik mereka. ${ }^{22}$ Pemberian layanan konseling CBT bagi korban bencana tsunami di Selat Sunda memerlukan enam tahapan: pertama, Engange client, layanan dimulai dengan menciptakan hubungan yang nyaman, penuh empati dan penghargaan serta hangat antara konselor dan konseli.

Kedua; Assess the problem, person and situation. pada tahap ini konselor melakukan asesmen terhadap masalah, orang lain dan situasi untuk mengetahui latar belakang dan tingkat masalah konseli. Ketiga; Prepare the klien for therapy, konselor mempersiapkan konseli untuk terapi, memberikan motivasi untuk berubah serta menjelaskan prosesnya. Keempat, Implement the treatment programme, konselor berusaha mengubah keyakinan maladaptive dan disfungsional dari

${ }^{22}$ Elfi Rimayati, Konseling Traumatik dengan CBT: Pendekatan dalam MereduksiTrauma Masyarakat Pasca konseli yang menjadi korban bencana tsunami menjadi sehat/normal kembali. Kelima, Evaluative Progres, konselor melakukan penilaian sejauh mana kemajuan dan perubahannya yang telah dicapai. Keenam, Prepare the client for termination, pada tahap akhir ini konselor perlu memberikan penguatan, dan memberitahukan kemungkinan adanya pengulangan kejadian yang menimbulkan traumatik, sehingga mereka bisa menyelesaikan masalahnya secara mandiri.

Respon masyarakat terhadap upaya pemberian berbagai bantuan sosial dari unsur masyarakat, penerintah, pihak swasta, dan organisasi lainnya, adalah sebagai berikut:

1. Kepala Desa Sidamukti Kec.Sukaresmi

Kepala Desa Sidamukti Bpk.Enjat Sujatna mengatakan pihaknya sangat berterima kasih kepada pihak-pihak yang sudah membantu meringankan beban warganya yang sempat terpuruk akibat di terjang bencana sunami kemarin. Dengan adanya bantuan dari organisasi sosial kemasyarakatan, seperti Aisyiyah Muhammadiyah Provinsi Banten, masyarakat banyak terbantu baik secara mental dan juga spritualnya. Disamping

Bencana Sunami Selat Sunda Indonesian Journal of Guidance and Conseling Vol.08 No 1 Th.2019 h.60 
itu pihaknya juga mengapresiasi kepada seluruh relawan yang dengan kerendahan hati bisa menghibur anak-anak kp.sidamukti dan juga para ibu-ibu agar mereka tegar dalam menjalani kehidupan ke depan yang jauh lebih baik lagi. ${ }^{23}$

2. Tokoh Masyarakat dan Tokoh agama Kec.Sukaresmi

Kordinator Bidang Kebencanaan Kecamatan Sukaresmi Bpk.Aslah sekaligus tokoh masayarakat setempat, mengatakan turut berterima kasih kepada tim organisasi sosial kemasyarakatan atas bantuan yang diberikan kepada warga yang terkena bencana, setidaknya dengan adanya bantuan ini membuktikan masih adanya kepedeulian antar sesama, khususnya kepada warga kampung sidamukti ini. ${ }^{24}$

\section{BPD Kp.Sidamukti Kec.Sukaresmi}

Sdr.Asep sekaligus tokoh pemuda mengatakan bahwa musibah yang terjadi di kp.sidamukti sudah pasti meninggalkan trauma yang sangat mendalam.yang mana akibat kejadian tersebut tempat tinggal warga sebagian

${ }^{23}$ Wawancara Enjat Sujatna Kepala Desa Sidamukti, hari minggu tanggal 06 Oktober 2019 di Kantor Ds.Sidamukti Kec.Sukaresmi Pandeglang

24 Wawancara dengan Nina Mulia penanggulangan Bencana Wilayah Aisyiyah Banten, hari minggu tanggal 24 Pebruari 2019 di SDN 4 Sidamukti Pandeglang

${ }^{25}$ Wawancara dengan Asep anggota BPD Desa Sidamukti, hari minggu tanggal 06 hancur diterjang ombak yang naik kedaratan. Oleh karena itu dengan adanya bantuan dari pihak-pihak terkait sungguh patut dan sangat disyukuri semoga apa yang niatkan, bisa menjadi ladang amal bagi kita semua. ${ }^{25}$

\section{Tokoh Perempuan Ds.Sidamukti}

Ibu endah salah satu warga yang pada saat terjadi bencana gelombang sunami selat sunda juga mengatakan sangat bersyukur, dengan adanya bantuan dari para relawan organisasi sosial kemasyarakatan yang jauh-jauh datang ke kampung kami memberikan bantuan baik makanan, pakaian, alat solat berupa mukena, bacaan-bacaan baik tentang solat maupun tentang ajaran nilai-nilai agama, yang semua itu sangat membantu dan bermanfaat bagi masyarakat. ${ }^{26}$

Masyarakat sangat senang dan merasa terbantu serta sangat di perhatikan dengan adanya bantuan khususnya dari organisasi sosial kemasyarakatan. Hal itu di buktikan dengan adanya bantuan pakaian,

Oktober 2019 di Kantor Ds. Sidamukti Kec.Sukaresmi Pandeglang

${ }^{26}$ Wawancara Endah Warga Desa Sidamukti, hari minggu tanggal 06 Oktober 2019 di Kantor Ds. Sidamukti Kec.Sukaresmi Pandeglang 
makanan,,alat untuk beribadah dan juga buku-buku belajar buat anak-anak serta buku panduan tata cara beribadah yang baik dan benar bagi ibu-ibu dan juga bapak-bapak disertai juga tidak lupa pemberian pembekalan melalui kegiatan psikososial psikososial bagi warga korban bencana dan yang terdampak tsunami Selat Sunda di Desa Sidamukti Kecamatan Sukaresmi Kabupaten Pandeglang. Dengan bantuan ini setidaknya bisa mengurangi bahkan menghilangkan trauma akibat bencana serta bisa mengangkat moral dan jiwa mereka terutama anak-anak. Bencana yang menimpa tempat tinggal serta orang tua mereka ini semoga hanya sebatas ujian dari tuhan sang pencipta, dan agar kita semua menyadari apa yang ada di dunai semua adalah ujian. Dan agar senantiasa selalu kuat bahwa mereka tidak sendiri, dan ada orang-orang diluar sana yang sangat peduli akan nasib mereka.

\section{KESIMPULAN}

Berdasarkan latar belakang masalah, identifikasi masalah dan pembahasan masalah yang telah diuraikan, fokus permasalahan serta menurut hasil yang diperoleh dalam peneletian ini dapat disimpulkan hal-hal yang : diuraikan sebagai berikut;

1. Dalam dua dekade terakhir terjadi sedikitnya sepuluh kejadian bencana tsunami di Indonesia. Sembilan di antaranya merupakan tsunami yang merusak dan menimbulkan korban jiwa serta material, yaitu tsunami di Flores (1992), Banyuwangi, Jawa Timur (1994); Biak (1996); Maluku (1998); Banggai; Sulawesi Utara (2000); Aceh (2004); Nias (2005); Jawa Barat (2006); Bengkulu (2007); dan Mentawai (2010).

2. Terdapat empat faktor pada gempa bumi yang dapat menimbulkan tsunami, yaitu: pusat gempa bumi terjadi di Iaut, gempa bumi memiliki magnitude besar, kedalaman gempa bumi dangkal, dan terjadi deformasi vertikal pada lantai dasar laut.

3. Tsunami sebagian besar disebabkan oleh gempa bumi di dasar laut. Selain itu tsunami juga bisa dipicu akibat tanah longsor di dasar laut, letusan gunungapi dasar laut, ekstrusi gas, jatuhnya benda-benda langit, ledakan nuklir, dan sumber pembangkit lainnya.

4. Bencana tsunami di Selat Sunda memberikan dampak psikologis bagi masyarakat di wilayah Banten dan sekitarnya. Traumatik akibat bencana tsunami yang mereka alami perlu mendapatkan penanganan yang serius. Bantuan berupa konseling untuk mereduksi traumatik mereka belum banyak dilakukan. 


\section{DAFTAR PUSTAKA}

Abdul Hakim, Makna Bencana Menurut Al-Qur'an: Kajian Fenomena Terhadap Bencana di Indonesia, Heurmeunetik,Vol.7, $\quad$ No.2 Desember 2013.

Abdul Majid, Dian Andayani, 2012, Pendidikan Karakter Perspektif Islam Bandung: PT Remaja Rosdakarya.

Abdul Munir Mulkan, Ahmad Syafii Maarif, 2010, I Abad Muhammadiyah Gagasan Pembaruan Sosial Keagamaan, Jakarta: PT Kompas Media Nusantara.

Abdul Mustaqim. Teologi Bencana Dalam Persfektif Al-Qur'an, Jurnal Nun, Vol. 1 No 1,2015.

Abdul Quddus, Ecotheology Islam: Teology Konstruktif Atasi Krisis Lingkungan, dalam Ulumuna Jurnal Studi KeIslaman Vol.16, No.2 Desember 2012

Abudin NATA, 2016, Sejarah pendidikan Islam Pada Periode Klasik dan Pertengahan, Rajawali Pers.

Ade Bujaermi, "Nilai-Nilai Pendidikan Dalam Cerita Mitos Masyarakat Banten, Tesis Program Pasca Sarjana Uin Sultan Maulana Hasanudin Banten, Serang, 2017.

Ahmad Riyadi Dasar Dasar Ideal dan Operasional Dalam Pendidikan Islam Jurnal Dinamika Ilmu Vol 11 No.2.2011 hal.4

Akmansyah, Al-Qur'an dan Al-Sunnah Sebagai Dasar Ideal Pendidikan Islam, Jurnal Pengembangan Masyarakat Islam Vol. 8, No.2 Agustus 2015.

Alie Humaedi, 2015, Etnografi Bencana Menakar Peran Para Pemimpin Lokal dalam Pengurangan resiko Bencana, Yogyakarta: LKiS.
Anggaran Dasar/Anggaran Rumah Tangga 'Aisyiyah, 2012, Jogjakarta : Pimpinan Pusat Muhammadiyah.

Bukhari Umar, 2011, Ilmu Pendidikan Islam, Jakarta: Amzah.

Chatarina Rusmiyati. Penanganan Dampak Sosial Psikologis Korban Bencana Merapi.Jurnal Informasi.Vol 17, No 02 Tahun 2012.

Elfi Rimayati, Konseling Traumatik dengan CBT: Pendekatan dalam MereduksiTrauma Masyarakat Pasca Bencana Sunami Selat Sunda Indonesian Journal of Guidance and Conseling Vol.08 No 1 Th.2019

Emzir, 2010, Metodologi Penelitian Kualitatif Analisis Data,Jakarta : Rajawali Pers.

Gazaly, Nofri Andy. Penguatan NilaiNilai Keagamaan Bagi Masyarakat Korban Bencana Gempa, Journal of Islamic \& Studies : Vol.3 No 2,2017 .

Gunawan, Ibnu Hasan, 2015, Percikan Pemikiran Pendidikan Islam : Antologi Konfigurasi Pendidikan Masa Depan (Jakarta: PT.Raja Grafindo Persada.

Hendripal Panjaitan "peranan 'aisyiyah dalam pendidikan Islam di kota Medan, Tesis institut agama Islam Negeri Sumatera Utara, Medan tahun 2013.

Heru Sri Naryanto, Kajian Bahya Tsunami Di Pantai Utara Kabupaten Serang, Jurnal Alami (ISSN: 2548-8635) Vol.3 No. 2 Th.2019

Ika Setiya Wati, Ragil Agustono, Peran Siti Walida Dibidang Pendidikan dan Sosial Dalam Perkembangan Aisyiyah Tahun 1917-1946, Jurnal Swarnadwipa Vol 1,Nomor 2, 2017 
Indiyanto Agus, Kuswanjoto dan Arkom, 2012, Agama,Budaya,dan Bencana. Bandung :PT.Mizan Pustaka

Lexy J. Moelong, 2006, Metodologi Peneletian Kualitatif, Edisi Revisi, Bandung: PT Rosda Karya,

Masduki Duryat, 2016, Paradigma Pendidikan Islam: Upaya Penguatan Pendidikan Agama Islam di Instansi yang Bermutu dan Berdaya Saing, bandung: Alpabeta.

Masterplan Pengurangan Risiko Bencana Tsunami, Menuju Indonesia Tangguh Menghadapi Tsunami, Badan Nasional Penanggulangan Bencana, Juni 2012.

Moh . Nazir, 2003, Metode Penelitian, Jakarta: Ghalia Indonesia.

Mohamad Nazir, 2014, Metode penelitian, Bogor : Ghalia Indonesia.

Muhaimin, 2012, Paradigma Pendidikan Islam: Upaya Mengefektifkan Pendidikan Agama Islam di Sekolah, Bandung: remaja Rosdakarya.

Muhammad Ali Saputra, Penanaman Nilai-Nilai Agama Pada Anak Usia Dini Di.R.A. DDI. Addariyah Kota Palopo. Jurnal Alqolam. Vol.XX. No.2 Desember 2014.

Muhammad Shofi Mubarok, Kepemimpinan Pendidikan Dalam Persfektif Enam Sistem Nilai Prof.Dr.Ahmad Sanusi, Jurnal Insania Vol 20,No 2, 2015.

Nadjamuddin Ramly, Hery Sucipto, Ensiklopedi Tokoh Muhammadiyah " Pemikiran dan Kiprah dalam Panggung Sejarah Muhammadiyah, Jakarta : Best Media Utama.

Nur Uhbiyati, 2013, Dasar-Dasar Ilmu Pendidikan Islam, Semarang : PT.Pustaka Rizki Putra.
Pasal 1 Undang-Undang Republik Indonesia Nomor 24 Tahun 2007 tentang Penanggulangan Bencana

Pedoman Struktur, Organisasi dan Mekanisme Kerja Lembaga Penanggulangan Bencana Muhammadiyah, Lembaga Penanggulangan Bencana Pimpinan Pusat Muhammadiyah:2012

Peraturan Kepala Badan Nasional Penanggulangan Bencana Nomor 4 Tahun 2008 Tentang Pedoman penyusunan Renacana Penanggulangan Bencana

Pusat Bahasa Departemen Pendidikan Nasional, 2008, Kamus Besar Bahasa Indonesia, Jakarta : Tim Penyusun Pusat Kamus Bahasa.

Qiqi Yuliati Zakiyah, A.Rusdiana, 2014, Pendidikan Nilai : Kajian Teori dan Praktik di Sekolah , Bandung: CV.Pustaka Setia.

Rahmi Mulyaih \& Liza Dinarizki P.Trauma Healing Dengan Menggunakan Metode Play Terapy Pada Anak-anak Terkena Damoak Tsunami Di Kecamatan Sumur Pandeglang, Jurnal Pengabdian Masyarakat: Vol. 1 No 1,2019.

Rahmi Mulyasih,Liza Dinarizki. Trauma Healing Dengan Menggunakan Metode Play Terapy Pada Anakanak Terkena Dampak Tsunan

Kecamatan Si

Pandeglang,Jurnal Pngaturaı Masyarakat, Journal of Islamic \& Studies : Vol.1 No 1,2019.

Rencana Kontinjensi Kota Cilegon Dalam Menghadapi Ancaman Gempa Bumi/Tsunami 2010, Tanggal 28 Juli sampai 1 agustus 2010 .

Said Agil Husain Al Munawar, 2005, Aktualisasi Nilai Nilai Qur'ani dalam Sistem Pendidikan Islam, Ciputat : PT.Ciputat Press. 
Said Agil Husin Al Munawar, 2005, Aktualisasi Nilai Nilai Qur'ani : Dalam Sistem Pendidikan Islam, Ciputat: PT.Ciputat Press.

Samhi Muawan Djamal, Penerapan Nilai Nilai Ajaran Islam Dalam Kehidupan Masyarakat. Jurnal Adabiyah. Vol.17. No.2,2017

Samhi Muawan Djamal, Penerapan Nilai-nilai Ajaran Islam dalam kehidupan Masyarakat di Desa Garuntungan Kecamatan Kidang Kabupaten Bulukumba, Jurnal Adabiyah Vol.17 No 2 Th.2017.

Siti Nur Masruhani, “ Nilai-nilai Pendidikan Islam Dalam Qs. AlMa'un" , Tesis Program Pasca Sarjana UIN SMH Banten, Serang,2017.

Siti Nur Masruhani, "Nilai-Nilai Pendidikan Islam Dalam QS.AlMa'un, Tesis Program Pasca Sarjana Uin Sultan Maulana Hasanudin Banten, Serang, 2017.

Syarif Made Masyah, 2007, Lewati Musibah Raih Kebahagiaan, Jakarta :PT.Mizan Publika.

Tim Penyusun, Pedoman Penulisan Tesis ; Program Pasca sarja UIN Banten: Serang.

Vigih Heri Kristanto, 2018, Metodologi Penelitian Pedoman Karya Tulis Ilmiah KTI, Yogyakarta : CV Budi Utama,

Wahyudi Memed, Asdani Soehaimi, Hendra Gunawan, 2019, Dinamika Geologi Selat Sunda Dalam Pembangunan Berkelanjutan, Bandung : Badan Geologi,

Wawancara dengan Aslah Suhartono, tanggal 24 Pebruari 2019 di SDN 4 Sidamukti Pandeglang

Wawancara dengan bhabinkamtibmas Polsek Sumur Ampi Jumhana S.Hut, 27 Maret 2019 di Polsek Sumur.
Wawancara dengan bidan Nani Maulana Asih Am.Keb, 27 Maret 2019 di Puskesmas Sumur

Wawancara dengan Iroh Syajarahtudur Sekretaris Pimpinan Wilayah Aisyiyah Banten, tanggal 20 Pebruari 2020 di Muhammadiyah Kec.Tirtayasa Kab.Serang

Wawancara dengan Nina Mulia penanggulangan Bencana Wilayah Aisyiyah Banten, hari minggu tanggal 24 Pebruari 2019 di SDN 4 Sidamukti Pandeglang

Wawancara Endah Warga Kp.Sidamukti, hari kamis tanggal 24 Oktober 2019 di Kec.Sukaresmi Pandeglang

Wawancara Enjat Sujatna Kepala Desa Sidamukti, hari kamis tanggal 24 Oktober 2019 di Kec.Sukaresmi Pandeglang

Wawancara Milla Fadhlia Sekretaris Daerah Aisyah Pandeglang tanggal 24 pebruari 2019 di SDN Sidamukti Kec.Sukaresmi Pandeglang Banten

Wawancara Wawancara dengan Nina Mulia penanggulangan Bencana Wilayah Aisyiyah Banten, tanggal 24 Pebruari 2019 di SDN 4 Sidamukti Pandeglang.

Website resmi desa Sidamukti di akses pada hari sabtu tanggal 08 Pebruari 2020

Wening Wihartati. Dakwah Pada Korban Bencana Alam dan Bencana Sosial, Jurnal Ilmu Dakwah : Vol.34 No 1, 2014.

Zuhairini, Sejarah Pendidikan Islam, Direktorat Jenderal Pembinaan Kelembagaan Agama Islam Departemen Agama : bumi Aksara. 